\begin{tabular}{c} 
International Journal of Engineering \& Technology, $7(4.37)(2018) 173-178$ \\
International Journal of Engineering \& Technology \\
WPC \\
Website www.sciencepubco.com/Index.Php/IJET \\
Research Paper \\
\hline
\end{tabular}

\title{
Recycling of Food Waste to Produce the Plant Fertilizer
}

\author{
Rand R. Ahmed*, Aziz I. Abdulla \\ Environmental Engineering Department, University of Tikrit, Tikrit, Iraq \\ *Corresponding author E-mail: randrafi3@tu.edu.iq
}

\begin{abstract}
Around 5000 tons of food waste is produced every day in Iraq which accounts for about (50\%) of the waste that we get rid of them. Waste sent to landfill for disposal may break down and produce methane gas that causes greenhouse effect, as well as cause odor, epidemics, and disease because of the disintegration. The research aims to produce organic fertilizer through the recycling of domestic refuse. It has been working through this research to collect the domestic refuse food which represent the nitrogen source, as well as the remains of cleaning and trimming of various trees and the remains of lawn mowers, and use of sawdust white wood which represent the carbon source. Have been working on dried and arranged in layers of perforated plastic containers for ventilation, it was moisturized with two different types of water and monitored fertilizer maturity for four months. Previously the fresh water was used for the purpose for moisturizing the mixture (chlorination water supply) later the domestic wastewater have been used. The comparison was made between the results of tests performed; the test has come up with the result that the use of "domestic wastewater" which it is rich in living organisms is the best and fastest in the process of manufacturing organic fertilizer than the use of "water supply", to contain the latter on the amount of chlorine of weakens the growth of microorganisms. And the use of dried plant waste, in the mixture as source of carbon was successful, and it gave the best organic fertilizer production results because these wastes are easy to decompose compare with sawdust wood. The felicitous fertilizer is it rich with nutrient such as nitrogen $2.3 \%$, phosphorus $13 \%$, and potassium $20 \%$, etc. There are some important factors affecting the process of production of fertilizer, including air ventilation, temperature, moisture content in the mixture. Carbon to nitrogen is a major factor, where each 20-30 part of the carbon should be taken into account for the decomposition of 1 part of the nitrogen to produce the compost properly, the high proportion of carbon about $30 \%$, causes low-temperature mixture, and it leads to slow compost composition, and less than $20 \%$ leads to excess nitrogen, which lost in the air in the form of ammonia, and the higher $\mathrm{pH}$ value, could be toxic to some microorganisms.
\end{abstract}

Keywords: Biodegradation, Domestic refuse, Domestic wastewater, Food waste, Plant fertilizer, Recycle process, Water supply, Vegetarianism waste.

\section{Introduction}

Environmental pollution caused by food waste has become increasingly prominent. How to effectively treat food waste has become one of the most important problems that must be addressed in the future development in Iraq. At present, the collection, transport, and treatment of urban cast food and other waste in Iraq are primarily implemented by municipality as a public service. Moreover, its treatment technique and method are based mainly on landfills. Therefore, the level of resource recovery, energy utilization and harmless treatment of food waste is low. This research investigates the recycle of food waste technologies and its practical application. The results demonstrate that food waste treatment should focus on its generation reduction from the source by recycle process. At the same time, an integrated waste management from the waste generation, collection, transport to the latest treatment must be implemented.

Trash or rubbish: " Is any excess or undesirable material and it is difficult to define what waste is because what is considered waste for some people is considered valuable to others."

Waste Management: Means control of collection and comfortable waste treatment in easy and low-cost ways. The aim is to reduce the negative impact of waste on the environment, society and public health.

The history of the production of compost since 1994, Where he started in (Ramat Hanadiv) by the collective of the green waste and remnants of pruning and reuse as a compost instead of burning and polluting the air.

Many have worked on recycling waste from different sources to produce compost and studying the importance of the subject. Found (Sultan bun Mohamed Al-eed 2012) through a study conducted on the recycling of domestic refuse using ordinary water as a source of moisturizing, however, organic manure is a vital substance and is added once during the year to the soil when the mineral fertilizers are added several times, which reduce the ability and soil enhancers after a comparison with the latter. Sultan studied the most important variables and factors that affect the speed of compost composition, including microorganisms, temperature, humidity and surface area. It was found that organisms such as bacteria found in the organic materials food of carbon and nitrogen to produce energy and reproduction. As for temperature, it was found that the higher rate of temperature that means higher rate of decomposition and the production of the compost, and the lower rate of temperature that means the lower rate of decomposition and fertilizer formation. Also, the outside air temperature also has an impact, in the summer, with high temperature of the external atmosphere, the activity of the bacteria stimulates the speed of compost formation. While in cold weather, it takes more time. As regards humidity, Sultan found that the bacteria needed of water to moisturize and if humidity is less than $40 \%$, the activity of bacteria decreases, If more than $60 \%$, the water replaces the air in the air gaps. Thus, aerobic bacteria die, and the anaerobic bacteria are 
activated, which in turn destroys organic matter but it slowly and produces unpleasant odors.

Historical background: Made (Ben Nasser Fahd Al-Kakes 2012), to recycling waste domestic refuse and food to production the organic fertilizer by aerobic and anaerobic decomposition by use ordinary water for moisturizing, Cakes found that the use of this organic matter resulted in improved the structure of the soil and improve the ability of the soil to retain water and increase the resistance of the plant. Also, it concluded that the aerobic decomposition produces insufficient heat. There is no emission of irritating gases, and the quality of compost produced is better than in anaerobic decomposition, anaerobic degradation also results in insufficient heat, emission of irritating gases, and the final product is poor. (Abdul Halim Fathi Gomaa Derby, in 2012), studied the production of compost using the leaves of various trees, land, green and a little of wood. Domestic refuse from fruit and vegetable peelings from onions, lettuce, peppers, etc., wood saws, newspapers and animal dung was used to provide microorganisms and to stimulate aerobic decomposition using normal water to moisturize the mixture. Derby used an iron container clamped open for ventilation of the mixture, and installed in the ground in a misleading place outside the house in the soil. After the decomposition of the raw materials, Derby obtained organic fertilizer with a brown color, crumbled and has an odor that resembles the smell of eggs. This is attributed to the lack of ventilation of the mixture that the container is installed in the ground, and cannot be turned for air circulation.

(Stoknes, K., Scholwin, F., Krzesinski, W., Wojciechowska, E and Jasinska, A.2016) Use a digester system with microorganisms to break down organic waste into fertilizer; the resultant fertilizer was used in a low - energy greenhouse to produce a range of food crops. This method is a potential way to utilize food waste and reduce energy consumption of food production as part of a circular economy. (Sopiah, Wan, and Noorazlin, 2016) Discuss how to produce fertilizer from food waste recycling through Bokashi and Berkeley method which is are easy to apply at home, and production fertilizer is only within one month or less with low cost. This study also suggested that producing fertilizer from food waste using Berkeley and Bokashi method has been proven to be successful. (c.R. Sudharmaidevi ,K,C.M.Thampatti,N.Saifudeen, 2017) studied the chemical decomposition as a potential method for the rapid conversion of food waste and recycling to organic fertilizer, resultant that the new thermochemical waste processing method provides a successful fertilizer by recycle food waste and quick and sustainable solution. The goal of this research is to recycle domestic food waste, which constitute approximately 50\% of the waste that we disposal during the day. As well as various waste vegetable, gardens and white wood mulch by using ordinary household water and domestic wastewater as a source of hydration for the production of the organic fertilizer which is the result of the biological decomposition of the organic matter, by the bacteria and some useful microorganisms that use carbon and nitrogen to produce energy to composition of the protein needed to build their body and multiply under certain environmental conditions of warmth, humidity and good ventilation. Compost it is a brown material with a smell that likes of soil and a spongy, smooth texture. Organic fertilizer plays an important role in the growth of micro-organisms and earthworms, eliminates insect eggs by high heat and reduces the risk of plant diseases. Organic fertilizer contains high numbers of bacteria necessary for the decomposition of organic matter found in nature, including leaves, dissolved roots, and plant residues, and re-revitalize soil composition after losing bacteria due to the use of chemical pesticides and increases the ability of the soil to retain water. Improving soil fertility and ventilation and stimulates the growth of plant roots well, organic fertilizer can be added at any time during the year, unlike the high-cost chemical fertilizers, which is harmful to soil and harmful to human health and pollutant to the environment and groundwater, and it can be added only at certain times of the season, the second goal is to spread the culture and environmental awareness and how to deal with the waste as a rich source instead of being a burden on the environment and contribute to the development of garden culture in homes and agricultural work, which in turn maintains a clean environment. This work falls into two parts; The first is the use of plant wastes and grass, which is already dried as a source of carbon, with household waste and the use of sawdust as a source of carbon in the presence of household waste and to compare between them, to give better results and faster in the composition of organic fertilizer. The second part of the research is the use of chlorination water supply as a source of moisturizing and the use of domestic wastewater as a source of moisturizing other times and comparing them, to give better results and faster in the production of plant fertilizer, so we have two types of testing. In this research, the remains of cleaning and trimming the various trees and the remains of mowing the grass, as well as the wood briquettes were collected, and on the other hand collect quantities of domestic refuse food, includes egg shells, onion peel, carrots, lettuce, tomatoes, peppers, oranges and cooked tea leaves. They were dried and arranged in layers of perforated plastic containers for ventilation. Four plastic containers were taken and regularly punctured for ventilation; two of modules were used wood briquettes and domestic refuse food filler. First: the water used as a source of hydration. The second: was use the domestic wastewater as a source of hydration. The following two models were used for domestic waste food, with leaves, grass and various plant wastes. As will be explained in detail later, and also the first model of which was the use of ordinary water for moisturizing, the second was the use of domestic wastewater, And monitoring the maturity of manure for four months. The four models were compared regarding the best filler and the best source of hydration to production and obtain organic fertilizers successful. The result of this research was: Obtained four models of compost, two of which proved their failure regarding shape, texture, general specification and measurement of some important properties (which use the ordinary water as a source of hydration with different filler). The other two models (which use the domestic wastewater as a source of hydration with different filler),. Once (with wood briquettes and domestic refuse food filler) needed a longer period for complete decomposition for the difficulty of decomposition of lignins in wood but the latter (with domestic waste food, and leaves, grass and various plant wastes) proved an organic fertilizer rich in vitamins and important elements of the plant of nitrogen, potassium, iron, phosphorus, carbon, and others because of the ease and speed of decomposition of organic matter and the use of domestic wastewater which rich in microorganisms that worked to decompose properly.

\section{Materials and Methods}

Materials used "raw materials": Various domestic refuse were collected during the daily household work including:

White eggshells: Eggshells were collected after using their contents and collected in a container of three eggs per day for four months. They were exposed first to the sun for three days on newspapers for dryness and ensure that there is no content, and then it was broken down smoothly to facilitate the process of decomposition and acceleration using an electric mill. Eggshells are a major source that equips the mixture with phosphorus. Green component of the mixture: Is the source of nitrogen, where the nitrogen supplies the microorganisms with a raw element of proteins and amino acids that needed to build their bodies and propagate. The green component mixture is also supplied with nutrient that is made from vegetable husks, tomatoes, carrots, onions, orange, a sharp peeling knife was used for taking profit of these green materials, and then it took the crusts and spread on the sun for about a week on the newspapers sheets for the purpose of completely dryness because it contains large amounts of water which causes high moisture mixture and thus block the aerobic gaps and the activation of anaerobic bacteria and the emergence of 
odors as a result of anaerobic degradation and the accumulation of flies and insects on the mixture.

The waste of cooked tea leaves consumed, where tea leaves were collected after boiling by using a metal sieve buckle and spread on the sunlight on the an iron dish to get rid of moisture in its content, tea leaves was used as a source rich with carbon.

Kitchen waste: It is a group of different wastes that were added in certain quantities because they supply the mixture with nitrogen, phosphorus, and potassium, etc., such as garlic, watermelon husks and a few remnants of fruit peel banana, pomegranate, and apples. Wood briquettes: The white wood sawdust, which was collected from the wood factory, it is also considered the brown component of the mixture and the main source is prepared the mixture with carbonate and collected in plastic containers until the time of the experiment and did not need to dry because it was already dry

Plant waste: it is included the collection of leaves falling from trees added to the leaves produced by the process of trimming the trees of Shapwi night, and climber cat leg, orange, and lemon, as well as the result of clips the grass by machine cutters, the plant waste is the carbon source of the mixture from which represents 20-30 parts of carbon per 1 part of the nitrogen in the mixture where the process of composting is ideally done in such conditions. This garden waste was collected and spread on newspapers to dry it from the water for ten days. Because containing water causes an increase in the water content of the mixture in the case of non-drying and increases the moisture content from the normal rate of $60 \%$, which leads to the water replacing the aerobic spaces and the transformation of the decomposition into anaerobic decomposition and produces the smell of unpleasant, addition to the start of anaerobic bacteria to slowly destroy the entire system, and damage the fertilizer.

* It is worth mentioning that must be avoid leaves of trees that have been sprayed with insecticides because they reduce or eliminate the growth of microorganisms that perform the process of decomposition of primary substances.

* It is worth noting that must be avoid the use of solid materials such as bone, chicken, milk, dairy products, and fat because they cause odors and bring rodents, insects and difficult decomposition by microbiology. It is also necessary to avoid containing the mixture on the remnants of cats and dogs because they contain diseases and insect eggs*

The most important nutrients of the raw materials in the mixture were examined to know the decomposition ratios of the organic matter during the research process. Also, it is to identify the percentage of the important substances in the mixture as shown in table (1)

Moisturizing water for the mixture: Water is a light film on the surfaces of waste this film facilitates the movement of bacteria in the mixture. Although the primary materials contained large quantities of water content, but it was dried well to maintain the: First standard moisture ratio of the mixture, which range from $40-60 \%$, this is because the primary materials used need varying amounts of moisturizing. Wood briquettes need more water than leaves and dried grass, while green materials and food waste do not need to be heavily moistened. Therefore, if noncontrol of moisture content of raw material and not liquidation, shall not be controlled by the required percentage of moisture which shall be not less than $30 \%$, Because the residues remain as they are without activating the bacteria and if more than $70 \%$ produce an anaerobic environment Second, the purpose of the drying of the raw material is to add the water supply of the regular to samples of the experiment and added the domestic wastewater for other samples as a source of moisturizing, then they are compared to each the best source of moisture mixture and the examined of the specifications and factors important for both exporters as in tables (2 and 3).

Tools used: Several tools were used in this research, they are:

- Sharp knife for chopping and peeling materials.

- Iron sieve to clean tea leaves.

- Machine grinding (mill) to grind eggshells.

- Ladle large plastic.
- Machine lawn mowers working with electricity.

- Large iron dishes for the publication of raw materials and drying.

- Plastic containers with a cover, one capacity of 5 liters.

- Electrocautery to perforate containers and obtain holes with equal and consistent form for ventilation.

Devices used: The researcher used many devices to conduct laboratory tests for the quality of domestic wastewater, water supply and the first material contained in the mixture before starting research. And next the process of composition of organic fertilizer was also used to measure the most important specifications obtained in the result; some tools were used likes:-

- Thermometer to measure the temperature.

- $\mathrm{pH}$ device to measure the value of $\mathrm{pH}$.

- The candidate papers to measure the amount of total suspended Substances.

- Spectroscopy device in the field of radiation to measure the proportion of polluting substances in water and wastewater analysis of nitrate, phosphate and other sulfates.

- Atomic absorption spectrometer for measuring chlorides.

- Graduate pipette.

- Cylinder included.

- Plastic containers are tightly closed with a capacity of 1 liter to take the models.

Workplace : It was made to preparation special place to work and execution the research, it is specification a small garden and preparation the typical condition from warmth, humidity, airfield and shadow to ensure the typical condition.

Works period: Initiation of the work in April and continue for four months which (April, May, June, July).

Method of action: We have already mentioned that the research was based on two different types of tests and comparing them where they were:

First: the use of plant waste and dried grass as a source of carbon for the mixture and the use of wood briquettes for the same reason and compare them is to give better results and faster in the composition of organic fertilizer.

Second: The use of ordinary domestic water as a source of wetting mixture and the use of domestic wastewater for the same purpose and comparing them, is to give better results and faster in the composition of organic fertilizer.

The period of work began during April, four containers around shape of equal size (capacity 5 liters) with a tight cover were taken These containers were first numbered from These containers were perforator with openings of equal size by electrocautery of a round dome and surrounded by a container of about 120 holes, their purpose is to get proper ventilation and allow the air to enter, because there is no doubt that proper ventilation is a very vital factor most microorganisms need oxygen, especially the aerobic, with the availability of oxygen is sufficiently, they produce energy and grow quickly and consume more materials, when oxygen is not enough, the aerobic bacteria die and quickly activate the anaerobic bacteria, which in turn destroy organic matter slowly, and produce odors.

Organic substances are food for bacteria and other organisms, these substances contain carbon, nitrogen and many other nutrient. Bacteria use carbon to produce energy and nitrogen to form the protein needed to build their bodies and multiply, So during this work domestic refuse was taken from the daily waste. The green component of the mixture, Potato peel, onion, eggplant, melon peel, tomatoes, peppers, carrots, vegetables, and oranges, represent the main source of nitrogen for the mixture and eggshells rich in calcium and phosphorus dried and finely grated using an electric mill. And the waste of cooked tea leaves was dried as a source of carbon; It is best to dry the food waste before starting work because it contains a large amount of water, which causes bad smell and the accumulation of flies and insects. The presence of water causes a difference in the moisture content of the mixture, the increase in humidity from the standard specifications works to fill the aerobic spaces by the water and close the pores, which 
leads to the conversion of decomposition to anaerobic decomposition.

Sawdust was taken out of wood briquettes from the carpentry factory, they were stored in plastic containers. Leftover leaves, trimming the trees of Shapwi night, and climber cat leg, orange and lemon, as well as the result of clips, and pre-dried grass for use as the source of carbon for the mixture (the brown component of the mixture). Living organisms use carbon papers and wood wastes such as sawdust as a source of energy, Plants that have been sprayed with insecticides are excluded because they reduce or eliminate the growth of microorganisms that decompose and cause odor.

After the preparation of containers and raw materials, making the model 1 and 2, which contained the leaves of trees and garden residues as dry material and domestic refuse food as a green material and take containers 3 , and 4 containing wood briquettes as dry material and domestic refuse daily as a previous green.

Taking the model 1 and 2 and placed trees and garden waste as a primary class layer equipped with carbon, and placed above it a layer of green domestic refuse materials rich in nitrogen, phosphorus, and potassium, etc. And put a layer of dry leaves then a green layer of domestic refuse, and so on to the end of the first container and the second. As for the third and fourth containers, the fill used was a layer of sawdust and a layer of domestic refuse. The process initiated development of a layer of sawdust as a source of carbon and then a layer of domestic refuse source of nitrogen, phosphorus, and potassium, etc. and then a layer of sawdust and then a layer of domestic refuse, Thus the process was repeated to the end of the containers, taking into account the distribution of materials in an almost equal and systematic manner as in Figure (1). Aerobic bacteria need to water to live, the mixture should be moistened, and the materials are used, but if the proportion of moisture diminish in the mixture, the activity of agrobacteria diminish, and if the moisture content increases, the activity of the anaerobic bacteria increases and decreases the activity of the aerobic bacteria, because water replaces voids aerobic, leading to anaerobic decomposition. The next step of the program of work is to select the quality of water used to process the moisture content that is necessary for decomposition processes, a about 1-2 liters of water is used for the first time, and it is left for two weeks closed. The components must be stirred every 3 to 4 days to allow the passage of air to help the decomposition because the presence of oxygen helps accelerate the disintegration of waste. In the event of a not good ventilation, issued by the fermentation of the air odors odious. If it is dry, add a little water to moisten the mixture for the four containers. As for the quality of moisten the mixture source used as the second part of the experiment, Where water supply normal "water piped" use sometimes, and domestic wastewater at other times, Where household sewage was used in container number (1). And water supply for container number (2), the use of domestic wastewater for container No. (3), the use of water supply for container No. (4), its purpose is to find out which water used gives better and faster results with changing the quality of the filling that is once sawdust and passed the other dry leaves as the source of the carbon. Thus, we have a container number (1) where tree leaves were used with domestic refuse and domestic wastewater. And a container number (2), used leaves of trees and domestic refuse and public water. And a container (3) was used for sawdust, domestic refuse, and domestic wastewater. And a container number (4) used for sawdust, domestic refuse and public water piped. After the formation of fillings and numbering containers and moisturizing the components and close tightly to the presence of openings of the sides to allow the process of ventilation for the purpose of decomposition, here the four models were left to begin the process of decomposition of materials and take advantage of sources of carbon, phosphorus, nitrogen, and vitamins for a period of almost four months. Note: In the case of a smell similar to the smell of molded eggs, it means the lack of air in the mixture and in this case the container is flipped, if the contents of the mixture dry, this means the lack of water and in this case adds water to the mixture with the flipping of the components.

Tests used: The work during the search on two types of tests:

Before starting the experiments, we took a sample of each raw material entered into the test and subjected to a laboratory test to determine the amount of nitrogen, phosphorus, potassium and the carbon-to-nitrogen ratio inside the experiment to determine the value of the nutrient that will compose the compost after a period each of these materials will be subject to microbiology as in table (1)

Analysis tests for the most important general specifications of the mixture:

Table 1: Measurement of the main characteristics of the raw materials involved in the experiment.

\begin{tabular}{|l|c|c|c|c|}
\hline Subject & Potassium & Phosphorus & Nitrogen & $\mathrm{C} / \mathrm{N}$ \\
\hline wood briquettes & $0,50-1,51$ & $0,17-0,43$ & 0,75 & $40-80 / 1$ \\
\hline Grass & 2.3 & - & - & $20 / 1$ \\
\hline Kitchen waste & 1.2 & 0.7 & 0.8 & $15 / 1$ \\
\hline Vegetables & 1.8 & - & - & $13 / 1$ \\
\hline tree leaves & 0.9 & - & - & $40 / 1$ \\
\hline Tomatoes & $1,84-2,30$ & $0,29-0,31$ & $0,01-1,28$ & 12 \\
\hline Pepper & 2,6 & - & - & 15 \\
\hline Carrots & 1,60 & - & - & 27 \\
\hline Onions & 2,60 & - & - & - \\
\hline Eggshells & - & 1.3 & 0.09 & - \\
\hline Tea leaves & 0.9 & - & - & 13 \\
\hline Orange & 0.5 & - & - & - \\
\hline
\end{tabular}

Table 2: Specification of domestic drinking water. (water supply).

\begin{tabular}{|c|l|c|}
\hline Seq. & Specifications & Measurement \\
\hline 1 & Turbidity of unity & 1 \\
\hline 2 & PH & 6.5 \\
\hline 3 & Electroconductivity with micromosus / cm & 723 \\
\hline 4 & Total soluble salts dissolved in $\mathrm{mg} / \mathrm{L}$ & 204 \\
\hline 5 & Total hardness in mg / L & 323 \\
\hline 6 & color & Nonexistent \\
\hline 7 & Smell & Acceptable \\
\hline 8 & Bait & Nonexistent \\
\hline 9 & Sulfate $\mathrm{mg} / \mathrm{L}$ & 125 \\
\hline 10 & Chlorides mg / L & 150 \\
\hline 11 & Calcium indigestion mg / L & 115 \\
\hline
\end{tabular}

Table 3: Analysis of the most important specifications of domestic wastewater

\begin{tabular}{|c|c|c|}
\hline Seq. & Specifications & Measurement \\
\hline 1 & Carbons mg / L & 100 \\
\hline 2 & Chloride mg / L & 7.3 \\
\hline 3 & Phosphate mg / L & 16 \\
\hline 4 & Sulfate mg / L & 6 \\
\hline 5 & Magnesium mg / L & 8 \\
\hline 6 & Potassium mg / L & 42 \\
\hline 7 & Sodium mg / L & 88 \\
\hline 8 & Total alkalinity mg / L & 287 \\
\hline 9 & Total particulate matter mg / L & \\
\hline
\end{tabular}

Table 4: Analysis of the first model including (vegetarianism waste) + (domestic refuse) + (domestic wastewater)

\begin{tabular}{|l|c|c|c|c|c|}
\hline Seq. & $\mathrm{N} \%$ & $\mathrm{PH}$ & $\mathrm{K} \%$ & $\mathrm{Po} 4(\mathrm{ppm})$ & $\mathrm{C} / \mathrm{N}$ \\
\hline 1 & 1,5 & 5 & 1,8 & 17 & $13 / 1$ \\
\hline 2 & 1,5 & 6,5 & 19 & 10 & $14 / 1$ \\
\hline
\end{tabular}




\begin{tabular}{|c|c|c|c|c|c|}
\hline 3 & 1,6 & 8,5 & 21 & 34 & $14 / 1$ \\
\hline 4 & 4,0 & 5 & 24 & 34 & $13 / 1$ \\
\hline 5 & 4,2 & 6,5 & 28 & 30 & $15 / 1$ \\
\hline 6 & 2,1 & 8 & 23 & 28 & $18 / 1$ \\
\hline 7 & 2,2 & 8,2 & 34 & 25 & $20 / 1$ \\
\hline 8 & 2,0 & 8 & 42 & 28 & $22 / 1$ \\
\hline 9 & 2,0 & 8,2 & 48 & 26 & $23 / 1$ \\
\hline 10 & 2,2 & 8 & 50 & 25 & $27 / 1$ \\
\hline 11 & 2,2 & 7,9 & 45 & 23 & $25 / 1$ \\
\hline 12 & 2,0 & 7,8 & 38 & 20 & $26 / 1$ \\
\hline 13 & 2,1 & 7,5 & 35 & 18 & $27 / 1$ \\
\hline 14 & 2,1 & 7,3 & 28 & 15 & $28 / 1$ \\
\hline 15 & 2,2 & 7,3 & 25 & 14 & $30 / 1$ \\
\hline 16 & 2,3 & 7,2 & 20 & 13 & $29 / 1$ \\
\hline
\end{tabular}

Table 5: the second model included analysis (vegetarianism waste) + (domestic refuse) + (water supply)

\begin{tabular}{|c|c|c|c|c|c|}
\hline Seq. & $\mathrm{N} \%$ & $\mathrm{PH}$ & $\mathrm{K} \%$ & $\mathrm{Po} 4(\mathrm{ppm})$ & $\mathrm{C} / \mathrm{N}$ \\
\hline 1 & 2 & 5,5 & 0,7 & 13 & $13 / 1$ \\
\hline 2 & 2,5 & 6,7 & 1,9 & 10 & $14 / 1$ \\
\hline 3 & 2,6 & 8,5 & 2,1 & 10,5 & $14 / 1$ \\
\hline 4 & 4,0 & 5,8 & 2,4 & 12 & $13 / 1$ \\
\hline 5 & 4,2 & 6,5 & 5 & 12,5 & $12 / 1$ \\
\hline 6 & 4,1 & 8,0 & 6 & 12,5 & $12 / 1$ \\
\hline 7 & 4,2 & 8,2 & 5 & 12 & $13 / 1$ \\
\hline 8 & 4,0 & 8,0 & 4,2 & 13 & $14 / 1$ \\
\hline 9 & 4,0 & 8,2 & 4,8 & 15 & $14,4 / 1$ \\
\hline 10 & 4,2 & 8,5 & 5,0 & 14 & $14,7 / 1$ \\
\hline 11 & 4,2 & 8,0 & 4,5 & 14 & $14,2 / 1$ \\
\hline 12 & 3,0 & 8,0 & 4 & 13 & $13,8 / 1$ \\
\hline 13 & 3,1 & 7,8 & 3 & 13 & $13 / 1$ \\
\hline 14 & 3,1 & 7,5 & 2,4 & 12 & $12 / 1$ \\
\hline 15 & 4,2 & 7,3 & 2,5 & 13 & $12 / 1$ \\
\hline 16 & 4,3 & 7,2 & 2,0 & 13 & $29 / 1$ \\
\hline
\end{tabular}

Table 6: the third model included analysis (wood briquettes) $+($ domestic refuse) + (domestic wastewater)

\begin{tabular}{|c|c|c|c|c|c|}
\hline Seq. & $\mathrm{N} \%$ & $\mathrm{PH}$ & $\mathrm{K} \%$ & $\mathrm{Po} 4(\mathrm{ppm})$ & $\mathrm{C} / \mathrm{N}$ \\
\hline 1 & 2,3 & 5,5 & 1,7 & 14 & $14 / 1$ \\
\hline 2 & 2,8 & 6,0 & 1,9 & 10 & $15 / 1$ \\
\hline 3 & 2,6 & 6,5 & 2,1 & 10 & $15 / 1$ \\
\hline 4 & 4,4 & 5,8 & 2,4 & 11 & $16 / 1$ \\
\hline 5 & 4,2 & 6,5 & 5,5 & 12 & $18 / 1$ \\
\hline 6 & 4,4 & 5,0 & 6,2 & 12,5 & $20 / 1$ \\
\hline 7 & 4,2 & 5,2 & 5,3 & 12 & $22 / 1$ \\
\hline 8 & 4,5 & 5,0 & 5,2 & 13 & $25 / 1$ \\
\hline 9 & 4,8 & 5,2 & 4,8 & 15 & $27 / 1$ \\
\hline 10 & 4,9 & 4,0 & 5,0 & 14 & $30 / 1$ \\
\hline 11 & 4,2 & 4,0 & 4,5 & 14 & $33 / 1$ \\
\hline 12 & 3,0 & 4,0 & 4,0 & 13 & $34 / 1$ \\
\hline 13 & 3,1 & 4,8 & 3,0 & 13 & $33 / 1$ \\
\hline 14 & 3,1 & 4,5 & 2,4 & 12 & $32 / 1$ \\
\hline 15 & 4,2 & 7,3 & 2,5 & 13 & $12 / 1$ \\
\hline 16 & 4,3 & 7,2 & 2,0 & 13 & $29 / 1$ \\
\hline
\end{tabular}

Table 7: containing the fourth model analysis (wood briquettes) + (domestic refuse) + (water supply)

\begin{tabular}{|c|c|c|c|c|c|}
\hline Seq. & $\mathrm{N} \%$ & $\mathrm{PH}$ & $\mathrm{K} \%$ & $\mathrm{Po} 4(\mathrm{ppm})$ & $\mathrm{C} / \mathrm{N}$ \\
\hline 1 & 2,2 & 5,5 & 1,7 & 12 & $11 / 1$ \\
\hline 2 & 2,0 & 6,7 & 1,5 & 11 & $12 / 1$ \\
\hline 3 & 2,6 & 8,5 & 1,1 & 10,5 & $12 / 1$ \\
\hline 4 & 3,0 & 5,8 & 2,0 & 12 & $13 / 1$ \\
\hline 5 & 3,2 & 6,5 & 5,0 & 12,5 & $12 / 1$ \\
\hline 6 & 3,1 & 8,0 & 6,0 & 12,5 & $12 / 1$ \\
\hline 7 & 3,2 & 8,2 & 5,0 & 12 & $13 / 1$ \\
\hline 8 & 4,0 & 8,0 & 4,4 & 13 & $14 / 1$ \\
\hline 9 & 4,0 & 8,2 & 4,8 & 14 & $14 / 1$ \\
\hline 10 & 4,2 & 8,5 & 5,0 & 13 & $14,7 / 1$ \\
\hline 11 & 4,2 & 8,0 & 4,5 & 14 & $14,2 / 1$ \\
\hline 12 & 8,0 & 8,0 & 4,2 & 12 & $13,8 / 1$ \\
\hline 13 & 7,8 & 7,8 & 3,2 & 12 & $13 / 1$ \\
\hline 14 & 7,5 & 7,5 & 2,4 & 12 & $12 / 1$ \\
\hline 15 & 7,3 & 7,3 & 2,5 & 13 & $12 / 1$ \\
\hline 16 & 7,2 & 7,2 & 2,0 & 13 & $12 / 1$ \\
\hline
\end{tabular}

Table 8: Organic fertilizer successful specification in comparison with the standard specifications.

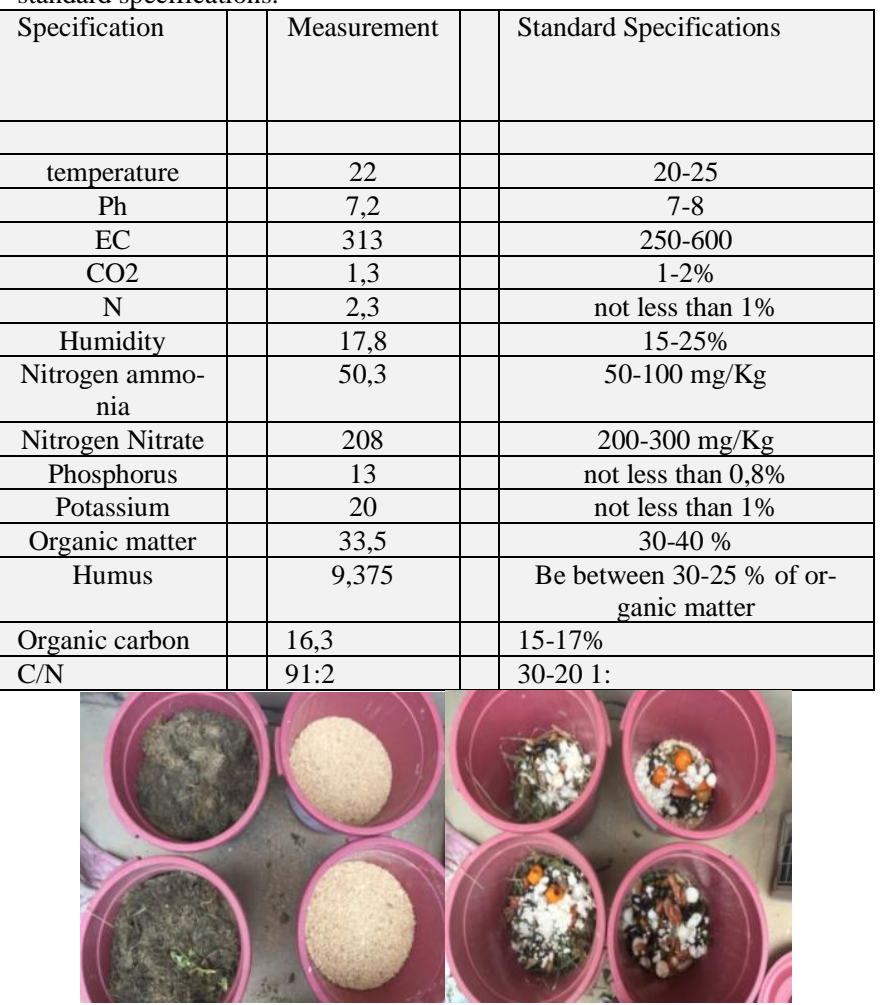

Fig. 1: (Completion the filling of containers

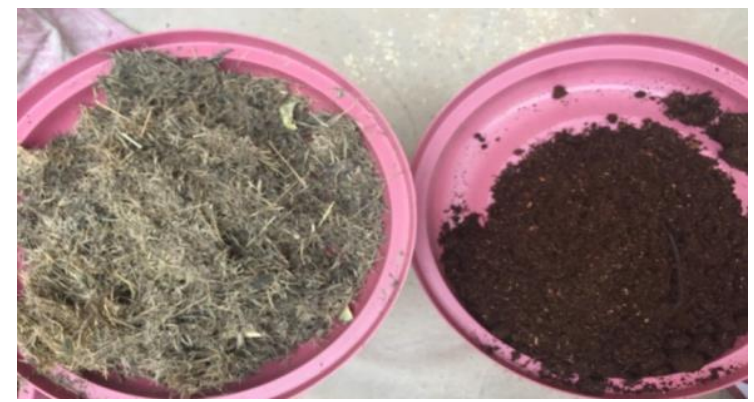

Fig. 2: The final results

\section{Results and Discussion}

Results: After approximately four months of work, control of the containers and stirring the contents, and taking into account the optimum conditions for the production of compost of the appropriate temperature, humidity, and ventilation, the results were obtained as shown in Figure (2). We find that one of container were successfully, analyzed and produce the organic fertilizer, and the failure of the remaining models and attributed to the following reasons: The container which contained vegetarianism waste and domestic refuse is a container (1), which use of domestic wastewater was the best and fastest result. It can be said that green materials such as leaves, grass, and others with high nitrogen content decompose faster than that it is in wooden materials that need more time. The ventilator also has an important role. There is no doubt that the availability of oxygen enough to microorganisms makes them grows rapidly and produces more energy and consumes more materials. And thus the speed of decomposition as well as the presence of sufficient number of holes in the containers and the rotation of components between periods and helped significantly to enter the air factor adequately. As for the temperature, during the research period, when the temperature of the atmosphere is highly that can be positive to form compost because the lower the temperature is, the worse, it will affect the compost composition because of the low microbial activity in the lower 
temperature. As for moisture content, the aerobic bacteria is responsible for the decomposition of organic matter, it needs water in sufficient quantities to form a film easy to move within the mixture, the addition of the use of domestic wastewater with the presence of vegetarianism waste and domestic refuse gave good results to plant fertilizer, within the standard specifications regarding texture, shape and key factors, this is because household wastewater contains a large number of living organisms that have worked to decompose organic matter and convert it into organic fertilizer under the appropriate environmental conditions. The absence of a foul odor from the mixture proved that the bacteria worked well and did not activate the anaerobic bacteria.

Container No. (2), contained vegetarianism waste and domestic refuse, used water supply as a source of moisture, gave weaker results, it took longer time to decompose. This is because the water supply contains sterile substances such as chlorine, which has slowed down the process of decomposition for killing most organisms that decompose organic matter. Because of the weak degradation, the carbon ratio is reduced, and therefore the excess nitrogen is lost in the air in the form of ammonia and raises its $\mathrm{pH}$ value, which can become toxic to some organisms and to not produce compost under the same environmental conditions for the rest of the models.

Container 3 and four also gave weak and slow results in decomposition because the filler used was wood briquettes as a source of carbon in the mixture. This is due to the difficulty of decomposition of sawdust, and it needs a longer period compare with leaves than trees and weeds, due to the difficulty of decomposition of the lignin found in it. The percentage of carbon degradation by microorganisms decreased, and consequently, lower the mixture temperature slows down which cause increase carbon percentage in the mixture and fail the organic fertilizer composition process.

It is not surprising that the use of wastewater in this experiment is better than using the water of the reservoir because it contains a high proportion of microorganisms responsible for the first and last decomposition of materials and production of manure. After obtaining this result, the specifications of compost were examiner to ensure that it conformed to the standard specifications, to get a successful fertilizer. A Sample was taken from the container (1), which gave a result closer to the formal specifications, texture, and smell of successful fertilizer. This sample was subjected to laboratory examination to obtain results which are acceptable and within the specifications as in table: (8). The remaining samples were not subjected to laboratory testing, because they did not initially meet the physical specifications regarding shape, texture, smell, color, and moisture.

\section{Conclusion}

The principle of recycling domestic refuse is a successful principle, which helps eliminate about $30 \%$ of domestic refuse instead of put it in the landfill, and becomes a burden on the environment. Natural manure is one of the good alternatives for chemical fertilizers available in the markets; it is no less useful than the commercial materials. If we put organic fertilizer in a container with water for seven days, we will get another type of paper fertilizer, which is known as nutrient solution, which is easier to fertilize and do the same purpose.There is some important factors affecting the process of the production of fertilizer, including air ventilation. The principle of air supply should be maintained in sufficient quantities with the mixture stirred between periods to avoid the low oxygen content of the mixture, which leads to the growth of the anaerobic bacteria by emitting a foul odor that resembles the smell of rotten eggs. Maintaining the appropriate moisture content in the mixture, which ranges from $40-60 \%$ to provide a suitable medium for microorganisms within the mixture, where less than $40 \%$ lead to dry mixture and kill organisms, and if the increase in the ratio of $60 \%$ leads to filling the gaps and pores with water, which leads to the closure and activation of anaerobic bacteria that begin to destroy the system slowly. Temperature is a main and very important factor, the temperature of the mixture should be maintained fairly high, however, in case of low temperature, the activity of bacteria decreases, and therefore there is less consumption of organic matter and failure of the system. The presence of carbon to nitrogen is a major factor, where each 20-30 part of the carbon should be taken into account for the decomposition of 1 part of the nitrogen to produce the compost properly. The high proportion of carbon about $30 \%$ causes low-temperature of mixture and it leads to slow compost composition, and less than $20 \%$ leads to excess nitrogen, which lost in the air in the form of ammonia and the higher $\mathrm{pH}$ value, which could be toxic to some microorganisms. The use of domestic waste as a source of nitrogen has been successful, as these wastes are rich in nitrogen and nutrient, this is confirmed by the initial analysis of the elements involved in the mixture. The use of dried plant waste, in the mixture as source of carbon was successful, and it gave the best organic fertilizer production results because these wastes are easy to decompose and do not need much time. Organic fertilizer is considered poor in carbon, if the wood briquettes are used as a source of carbon, because of the difficulty or delay of decomposition of wood briquettes compared to the green materials in the mixture, it needs a longer period of vegetarianism waste used for the same purpose, so add urea as an additive or add some animal residue to the mixture, to make up the shortfall in the amount of nitrogen and carbon and microorganisms. The use of domestic wastewater is the best and fastest in the process of manufacturing organic fertilizer because it is rich in living organisms and bacteria that analyze organic substances that use carbon as a source of energy and nitrogen to produce protein to build its bodies and thus consume organic matter in the mixture. The use of water supply is the weakest in the manufacture of manure because it contains deadly substances sterile organisms, namely chlorine.

\section{References}

[1] Abdelkader A. Gazei, (2008), principles of environm -ental sciences, while publishing house, 1(3):328.

[2] Bryan F Staley, Morton A Barlaz, (2009), Composition of municipal solid waste in the United states and implication for carbon sequestration and methane yield, Journal of Environmental Engineering 135 (10):901-909.

[3] CR Sudharmaidevi, KCM Thampatti, N. Saifudeen ,( 2017), rapid production of organic fertilizer from degradable waste by thermochemical processing, International Journal of Recycling of Organic Waste in Agriculture 6(1):1-11

[4] Fahad bun Nasser al Kake, (2012), the system of organic fertilizer production, colleges of science for agriculture and feeding ,University of Assud king.

[5] Fathi Abdul Halim gumaa herby , (2012), physical properties to compost and it is effective in improving some of physical properties to soil. College of agriculture and veterinary medicine , University of Al- Kassem.

[6] K Stoknes , F Scholwin , W Krzesinski , E Wojciechowska , A Jasinska (2016), Efficiency of a novel "Food to waste to food " system including anaerobic digestion of food waste and cultivation of vegetables on digestate in a bubble - insulated greenhouse Waste Management 56:466-476.

[7] Soultan bun Mohamed Al-eed , (2012), The fermenting manure (compost), center of the agriculture and organic matter investigation. Al - Kassem center investigation

[8] Wan Nazriah wan Nawawi, Noorazlin Ramli, (2016), production fertilizer from food waste recycling using Berkeley and Bokashi method, Faculty of hotel and tourism management, University of Teknologi Mara, Malaysia, , 72(4). 